\title{
LEPROSY'S ARTHRITIS WITH THE MYCOBACTERIUM IDENTIFIED IN THE SYNOVIAL FLUID
}

Mariana Oliveira Miranda ${ }^{1, \star}$, Gustavo Luiz Behrens Pinto ${ }^{1}$, Victor Pereira Mattos ${ }^{1}$, Lucas Guimarães Andrade Ferreira ${ }^{1}$, Mittermayer Barreto Santiago ${ }^{1}$

1.Universidade Federal da Bahia, Salvador, BA, Brazil.

*Corresponding author: marianam_o@hotmail.com

\section{BACKGROUND}

Leprosy is a chronic infectious disease caused by Mycobacterium leprae, that mainly affects the skin and peripheral nerves. Arthritis is the third most common symptom of leprosy; it is characteristically "reactive" and generally involves small peripheral joints. The authors describe a case of arthritis associated with leprosy ( $A A L)$ with the identification of the Mycobacterium in the synovial fluid.

\section{CASE REPORT}

A 29-year-old man, without comorbidities, undergoing regular multibacillary leprosy treatment with ofloxacin, clofazimine, and rifampicin, was admitted to the hospital in September 2020 with symmetrical polyarthritis in the knees, ankles, elbows, feet, and hands. He reported onset of symptoms seven days before hospitalization, with pain and swelling in his left knee. The symptoms progressed to aforementioned joints, associated with fever and erythema nodosum. Treatment with prednisone $1 \mathrm{mg} / \mathrm{kg} / \mathrm{day}$ and thalidomide $300 \mathrm{mg} /$ day were started and multidrug therapy for leprosy was maintained. Exams revealed C-reactive protein $120 \mathrm{mg} / \mathrm{L}(<5 \mathrm{mg} / \mathrm{L})$, rheumatoid factor (RF) $10 \mathrm{UI} / \mathrm{mL}(<20 \mathrm{UI} / \mathrm{mL}$ ), anticyclic citrullinated peptide (anti-CCP) antibody $0.6 \mathrm{U} / \mathrm{mL}$ $(<10 \mathrm{U} / \mathrm{mL})$, other laboratory tests were normal. Study of synovial fluid of the left knee revealed LDH 1664 UI/L (230-460 UI/L) and positive bacilloscopy for BAAR (Fig. 1). X-ray of hands and left knee showed no erosions (Figs. 2 and 3). The patient evolved with gradual clinical improvement (Fig. 4).

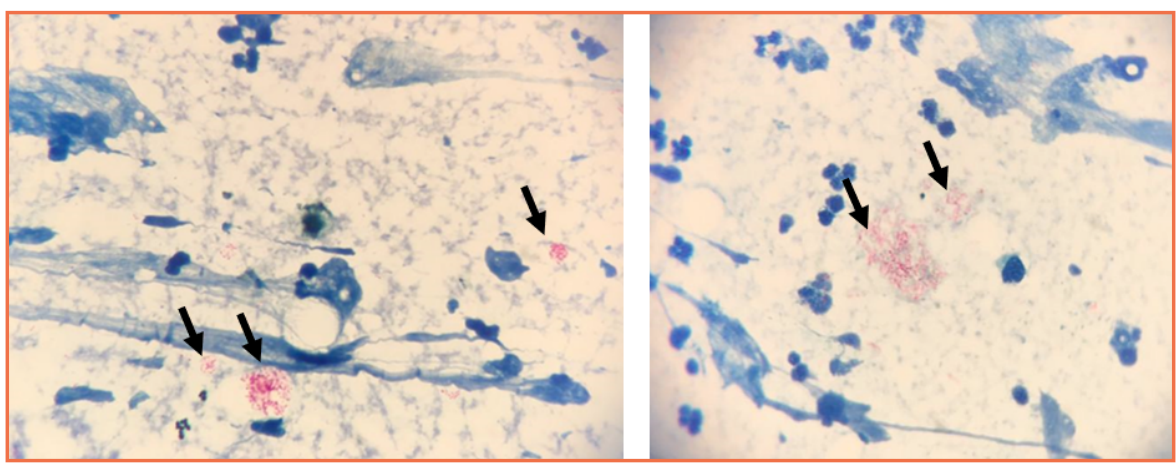

Figure 1

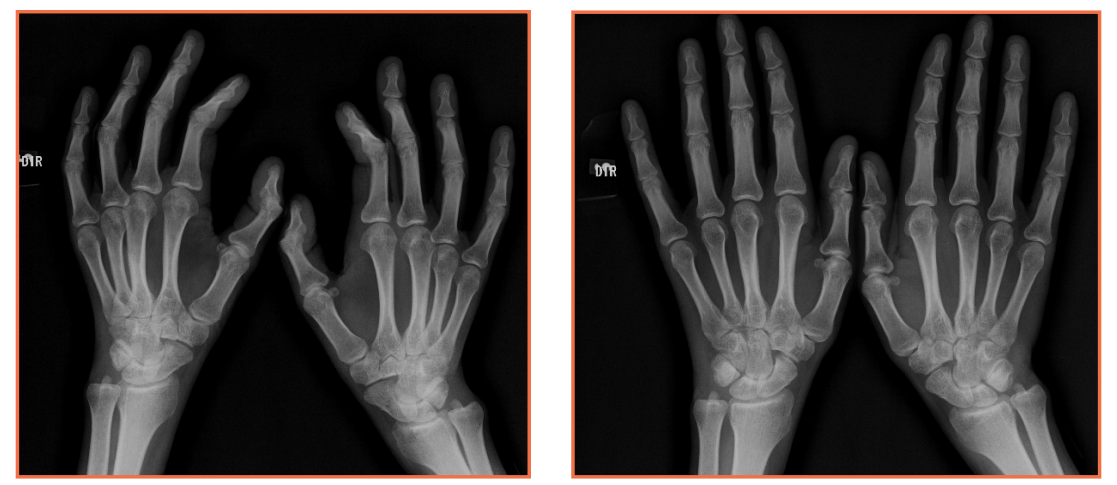

Figure 2 


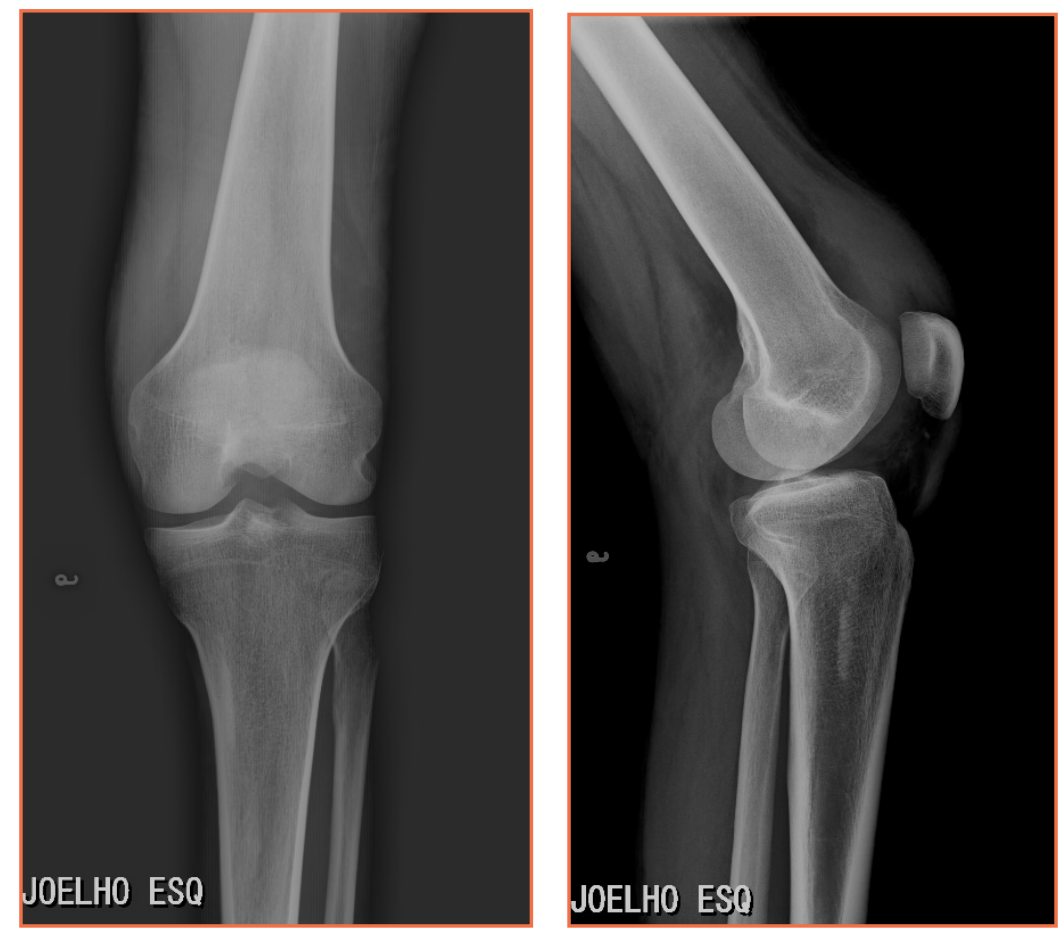

Figure 3.
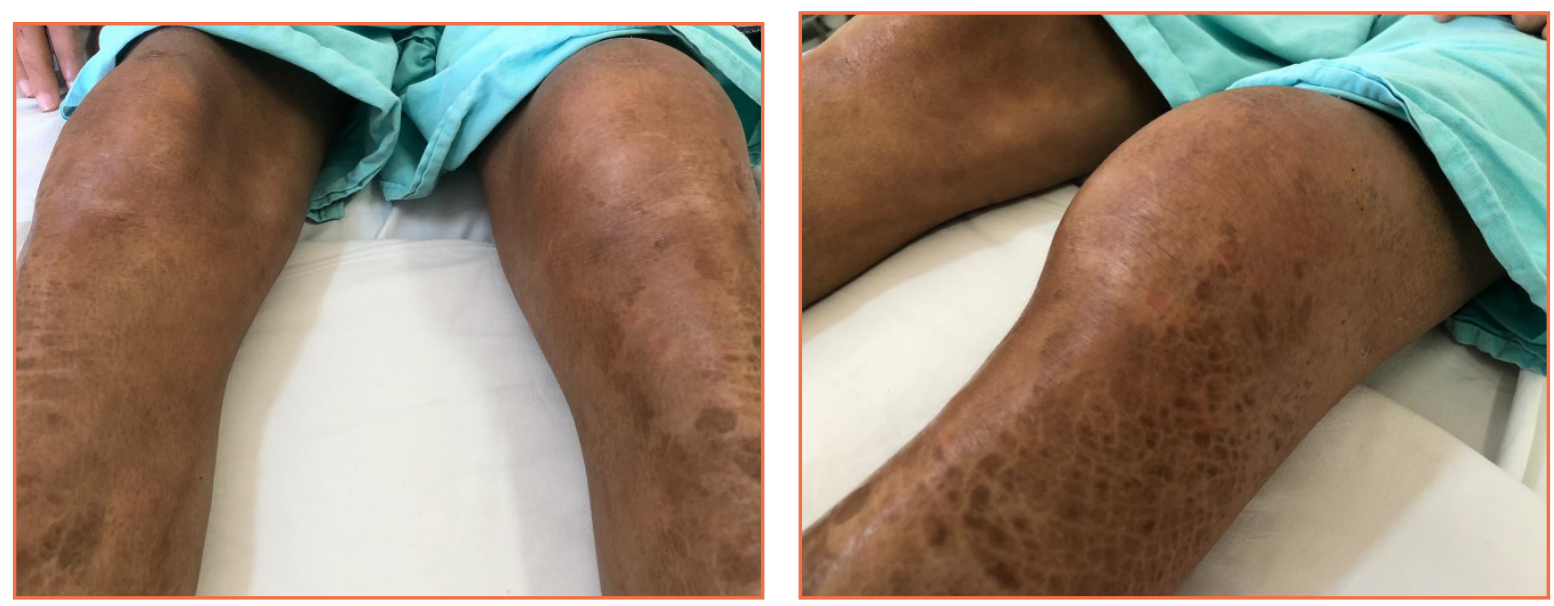

Figure 4.

\section{CONCLUSION}

Arthritis associated with leprosy can be neuropathic, septic or inflammatory, and usually has a nonerosive character. Leprosy patients may occasionally have positive antinuclear antibodies, RF, or even anti-CCP antibodies, which were negative in the present case. The immune response to $M$. leprae, through T cell reactivity, raises a "reactive" state. Arthritis as well as erythema nodosum are immunological reaction type II. Small peripheral joints are affected more frequently and, less commonly, knees, ankles, and shoulders. Treatment consists of the use of glucocorticoids associated with thalidomide. To our knowledge, the presence of M. leprae in the synovial fluid has been reported in the literature only in one previous case report. 